Warner, G.S., J.E. Faber, and M.J. Pelczar, Jr. A serological study of certain members of the nonpathogenic Neisseria group. Presented at the 50th General Meeting of S.A.B. May, 1950.

\title{
INTERIM REPORT OF THE SUB-COMMITTEE ON THE FAMILY NEISSERIACEAE
}

\section{Presented in Rome, September 7, 1953}

The first report of this Sub-Committee was presented at the 5th Congress in Rio during 1950. The principal recommendation made in this report was a proposed reclassification of Neisseria meningitidis according to the International Bacteriological Code of Nomenclature. The Proceedings of the Rio Congress have not been published as yet, so that bacteriologists working in this field have not had an opportunity to beçome familiar with this $A, B, C, D$ nomenclature. This proposed classification will, however, appear in the forthcoming Seventh Edition of Bergey's Manual, with its relationship to previous classifications presented in tabular form. The Section on Neisseriaceae in this Seventh Edition of Bergey's Manual has been revised by Dr. Branham and Dr. Pelczar, and reviewed by Dr. Murray. Several other recommendations made by our Sub-Committee have been included.

Although the members of this Sub-Committee have been very busy with other projects of various sorts during the three years since the Rio Congress, all have maintained a lively interest in Neisseria with the result that this interim report contains appreciable progress along several lines.

Classification: Through the cooperation of the Institut Pasteur in Paris and the Institut Pasteur Annexe in Dordogne, 8 strains of meningococcus representing the Type $\mathrm{C}$ of $\mathrm{Ni}$ colle, Debains, and Jouan (1918) were received and studied by $\mathrm{Dr}$. Branham. They were found to bevery closely related to, and probably identical with, the group that has been designated during recent years as II alpha. Thus the designation of Group II alpha as Group C, as proposed by our Committee at the Rio Congress, seems fully justified.

Dr. Bensted has been making intensive effort to find strains of Type IV in order that a suitable study can be made. 


\section{BACTERIOLOGICAL NOMENCLATURE AND TAXONOMY}

Dr. Pelczar has been searching for anaerobic Neisseriae but has found only strains that seem to be Veillonellae.

Epidemiology of Serologic Groups: Several members of the Sub-Committee have had access to newly isolated meningococci which they have typed. See table below:

\section{Period I II IIa IV Unclassified Total}

$\begin{array}{llrlllll}\text { Cohen } & 1950-52 & 1 & 29 & 20 & -- & 3 & 53 \\ \text { Bensted } & 1952 & 15 & 75 & -- & -- & -- & 90 \\ \text { Branham } & 1952-53 & 1 & 15 & 11 & -- & -- & 25\end{array}$

Incidence of meningococcal infection during 1952 and at present in the United States of America is higher than for the previous few years, although it cannot be said to have reached epidemic proportions. Group I, the usual epidemic strain, is conspicuously absent. Miss Cohen found one Group I strain in a total of 53 strains during these last 3 years, and Dr. Miller and Dr. Branham each encountered one such strain during 1952. In England, Group I has been more common, as Dr. Bensted found 15 strains of $I$ and 75 of 2 during that year. The 2 strains which he obtained from the outbreak in Southern Sudan were of Group II. No strains of Type IV were encountered.

Maintenance: Preservation in a "lyophile" or "freeze-dried" state is sodesirable that all workers are making every effort to keep their cultures in this way. Lack of facilities for this procedure handicapped Dr. Bensted's attempts to receive viable cultures from the Sudan. Dr. Prévot has observed that his collection of Veillonella strains has survived for a long period in such a "freeze-dried" state, whereas all of his strains of Neisseria that were stored by that method have been lost.

Metabolism and Nutritional Requirements: Both Dr. Thjotta and Dr. Pelczar have given much attention to this phase of study. One of Dr. Thjotta's assistants has been studying the metabolism of the meningococcus, and another has been investigating the "external" and "internal" antigens of the meningococcus by both immunological and physico-chemical means. This work is still in progress.

Dr. Pelczar's metabolic studies have dealt chiefly with N. gonorrhoeae, $N$. perflava and $N$. catarrhalis. He and his students have established that the compound putrescine is a 
necessary growth substance for $N$. perflava; they have studied and reported the amino acid requirements for $N$. perflava and $N$. catarrhalis; and have shown that acetic acid and $\mathrm{CO}_{2}$ represent the end products of glucose metabolism with $\mathrm{N}$. perflava and that with minimal amounts of glucose complete oxidation is effected. In contrast $N$. gonor rhoeae was unable to oxidize acetate. The only amino acidoxidized by the gonococcus was glutamic acid.

Suggestions and plans for future work: Dr. Thjotta and his assistants have begun a study of serological types of meningococci occurring in Norway. They have collected a number of strains, many from throat cultures, and have stored them in a "freeze-dried"state for future study. Dr. Thjotta wishes to type his strains on the basis of American type sera, and Miss Cohen has offered to furnish these to him.

Dr. Pelczar plans a reexamination of the aerobic pigmented species of Neisseria (N. perflava, N. flava, N. subflava) with the idea of establishing a definite opinion as to the validity of species designations in this group. He would like to receive additional strains of $\mathrm{N}$. subflava. Dr. Branham suggests that $N$. flavescens and $N$. hemolysans be studied with this group.

Other suggestions that have been made by both Dr. Murray and Dr. Pelczar are: 1) a search for anaerobic members of the genus Neisseria. Dr. Prévot's collection was destroyed during the war, and there are no cultures known to be in existence; 2) a search for Neisseria and Veillonella in animals other than man. 3) The examination of the validity of the named varieties of the two species of Veillonella is also suggested by Dr. Murray who feels that identification would be difficult on the basis of the characteristics described.

A suggestion comes from Miss Cohen that the Committee may wish to consider, in planning future studies, Dr. Hattie Alexander's work on the transformation of meningococcus types, published in Jour. Exper. Med., 1953, 97:797-806, "Indication of new type specificity of Neisseria meningitidis by desoxyribonucleic -acid-containing extracts."Miss Cohen has been especially interested in these studies because a number of years ago she noted a spontaneous occurrence of Group I microorganisms in a Group II strain in the course of experiments on the viability of meningococci in sodium chloride solutions. 
Subjects that were discussed during the Rome Congress:

All of the above suggestions for further work were discussed at the meeting of the Committee in Rome since, with the exception of Dr. Pelczar's plan for work with the pigmented Neisseria, the other proposed studies are neither planned nor assigned. Dr. Pelczar would like to hear the views of others regarding species designation in the aerobic pigmented group; i.e., does anyone have recent data which favors either the classification as presented in Bergey's Manual, or the concept of Wilson and Miles that these strains are all varieties of one species?

The desirability of designating some one place as a central "clearing house" for such cultures of the Neisseriaceae that seem to deserve study was emphasized at this meeting, and it was decided that such cultures be sent to Dr. Sara E. Branham at the National Institutes of Health, Bethesda 14, Maryland, U.S.A. Dr. Branham will receive these cultures, together with information concerning them, and assign them to those members of the Committee whose special field of interest is most nearly related to them. Thus valuable strains will not be lost just because no one knows where to find them. It is hoped that meningococci of the French Type $D$ and of the Gordon-Murray Type IV may be found. Strains of N. subflava are especially needed for Dr. Pelczar's study of relations between the pigmented species, and it is desirable to find other strains of the $\mathrm{N}$. hemolysans described by Dr. Thjotta. Anaerobic Neisseria are especially wanted since the anaerobic Gram-negative cocci found by both $\mathrm{Dr}$. Murray and Dr. Pelczar have all been Veillonellae. It was felt that a study of the species validity of the Veillonellae is indicated. Dr. Murray's recently isolated sheep strain of a Neisseria, and the $N$. caviae described by Dr. Pelczar definitely indicate further search for Neisseria in animals.

Considerable concern was expressed as to a reliable source of diagnostic sera for studies with these microorganisms. These are essential if comparative studies are to be made. At present there is no commercial source available.

The committee thinks that all of these proposed problems are well worthwhile. Those who can undertake work along these lines should be encouraged to do so.

Committee Members: E.G.D. Murray, Chairman, H.J. Bensted, R. St. John-Brooks, Sophia M. Cohen, S. T. Cowan, M.H. Gordon*, C.P. Miller, M.J. Pelczar, A.R. Prevot, Th. Thjøtta, Sara E. Branham, Secretary. 